\title{
A Typology of Practices of Legitimation to Categorise Accountability Relations
}

\author{
Siddharth Sareen
}

\begin{abstract}
This chapter presents the central element of an accountability analysis approach - a typology of four practices of legitimation: discursive, bureaucratic, technocratic and financial. These are empirically derived and defined in generic terms as social relations premised on accountability. Their study can characterise accountability under energy transitions. Discursive legitimation practices normalise certain perspectives over others through textual and spoken interventions across a variety of forums. Bureaucratic legitimation practices, often codified and sequential, validate some actions and actors and constrain others. Technocratic legitimation practices perform systematic checks and approval of actions that entail technical expertise. Financial legitimation practices, often spatially remote and materially elusive, enable actors to block action or to fulfil financial requirements and proceed with material actions, shaping sectoral change.
\end{abstract}

Keywords Practices of legitimation $\bullet$ Discursive $\bullet$ Bureaucratic $\bullet$ Technocratic $\bullet$ Financial

\footnotetext{
S. Sareen $(\bowtie)$

Department of Geography, Centre for Climate and Energy Transformation, University of Bergen, Bergen, Norway e-mail: Siddharth.Sareen@uib.no

(C) The Author(s) 2020

S. Sareen (ed.), Enabling Sustainable Energy Transitions, https://doi.org/10.1007/978-3-030-26891-6_2
} 
There is an endless variety of practices of legitimation. But they draw on a number of common registers. Four such registers surfaced clearly from empirical research on solar energy uptake in Portugal during 2017-2019. These empirically derived registers are put forward as a typology of practices of legitimation. They are:

- Discursive legitimation

- Bureaucratic legitimation

- Technocratic legitimation

- Financial legitimation

Without elaborating the empirical basis for this typology, detailed elsewhere (Sareen in review), and without extending the initial foray into the Portuguese case, this chapter unpacks each of these four types of practices: what do they mean? Furthermore, it puts forward a few preliminary suggestions for how this typology is supported by extant research on accountability and legitimacy within environmental governance. Environmental governance research has on the whole been rather laggardly in taking up the important question of sustainable energy transitions at disaggregated scales (Falkner 2014; Smith and Stirling 2010), so this connection between its treatment of accountability and legitimacy and their application to the energy sector is overdue (Szulecki 2018). It is a task that requires multiple perspectives and many person-years of research. This book enlists the support of select colleagues who have an appreciation of both environmental governance and energy transitions scholarship. This chapter kickstarts the conversation by laying out the types of practices of legitimation. Then, Part II opens with an explanation of the invitation (Chap. 3) issued to the authors of five subsequent case chapters, each of which presents a perspective on accountable governance under energy transitions, drawing on the case author's own empirical research (Chaps. 4, 5, 6, 7 and 8). The concluding Part III synthesises learning about the analytical usefulness of practices of legitimation across the five cases (Chap. 9), then features collective reflection on how future environmental governance scholarship can generate analytical insights on accountability (Chap. 10). The book seeks both to guide the uptake of accountability within theoretical and applied energy transitions research in a broad range of fields and disciplines, and to inform strategic action, thereby contributing to both analysing energy sector transitions and enabling accountable governance towards sustainability. 
With each type of practice of legitimation below, the intent is to fashion tools that can deconstruct what acts are being justified and validated (i.e., legitimated) by whom, to whom and in what manner. Each type of practice surfaces a specific register along which it evinces accountability relations that display commitment to sustainable outcomes. Within any given energy sector context, each type of practice is empirically observable to a sufficient degree to identify specific problem areas, accountability lacunae, scope for further gains and to challenge claims, and to pose normative questions of who gets to decide, and who should be consulted or otherwise involved.

\subsection{Discursive Legitimation}

Discursive legitimation refers to a set of practices that normalise certain perspectives over others through textual and spoken interventions across a variety of forums. These forums range from highly technical discussions among a narrow group of actors to mainstream debates for audiences as wide as the general public in the pages of national newspapers. Practices of legitimation manifest in many ways on these platforms: speaking in favour of one choice over another, thus advocating for something; referring to some things as commonplace and thereby stabilising them as a public imaginary; talking down some possibilities as being a threat to other desirable outcomes, thus creating or strengthening cognitive links; repeating the need for something as a matter of social necessity and thereby building public support for it; and dismissing some options as wishful thinking uninformed by reality, thus tightening the discursive space that might allow their propagation. These practices are all relational in the sense that they are enacted by actors in relation to audiences, and also because they position ideas in specific relation to other ideas.

A politician backing continued reliance on fossil fuels may, for instance, decry renewable energy sources as posing a debt burden on the public. A federation of solar energy developers may issue a statement against this, pointing out that they are able to compete with coal thermal plants without any public subsidies. Coal thermal plant owners may lobby national regulators to maintain the status quo in the energy sector, which has historically rewarded their power source as relatively 'reliable'. Energy market analysts may point out that this logic has changed, as greater interconnections between electric grids allow for more flexibility in energy sources. Those concerned with energy security might contend that more 
interconnections pose a threat to sovereignty due to increased reliance on neighbouring countries. Geopolitical experts might counter this argument by pointing out that greater interdependency can in fact foster regional cooperation. Each of these actors would be articulating their particular interests in relation to other competing or complementary perspectives, picking platforms and orders of worth that favour their message or ones that are crucial for securing particular desirable outcomes (von BendaBeckmann 1981; Boltanski and Thévenot 2006; Patriotta et al. 2011), be it parliamentary hearings, newspaper columns, online blogs, public consultations on new sectoral policies, electoral rallies, thematic conferences, annual expos or even urban festivals.

What makes these practices relevant for the examination of accountability in energy transition is that they lend themselves to empirical study (Moezzi et al. 2017). They allow a contextualised appreciation of different actors' interests and how they articulate them in a disaggregated manner. This extends to actors within organisations as well, as a given organisation rarely consistently represents a single perspective on a complex issue such as energy transition. If one understands energy sector governance as comprising an assemblage of actors (cf. Rose 1999) - governmental institutions, emerging authorities such as ad hoc commissions for specialised decisions, private companies, citizen associations, administrative bodiesthen practices of discursive legitimation offer insight into the numerous and shifting relations between this diverse mix of actors. Tweets by a key decision-maker, for instance, have lately emerged as a new way to keep up with the latest developments in a fast-changing sector, and offer new opportunities for public responsiveness-key figures can note and respond directly to comments by ordinary individuals-while also providing insight into the views of individuals within formal organisations (Morgan et al. 2018). Discursive legitimation is also susceptible to hegemonic tendencies-particular accounts can 'go viral' and spread rapidly, often exercising significant influence by shaping readers' or listeners' perceptions. Meanwhile, more detailed and often better substantiated claims such as those in academic articles can remain largely disregarded even by key decision-makers who usually have busy schedules and little time to access paywalled manuscripts that use heavy language.

Practices of discursive legitimation thus play a key role in energy transition: validating particular acts and shoring up the credibility of institutional authorities and their decisions against critique; issuing challenges to specific decisions and even decision-making processes and suggesting 
alternatives, thus opening up space for debate and the emergence of competing actors; and closing down particular claims by pointing to countervailing accounts, often more established ones with some formal backing. Observation and analysis of which actors legitimate what sort of action and on what basis, which actors level competing claims, and the platforms they pick to address specific target audiences, can furnish a telling picture of a given energy transition. Is it driven by a culture of informed public engagement, healthy debate, friendly critique and an effort at reflexive learning by authoritative institutions in the sector? Or are there several opposing camps, with those currently in a position of authority trying to maintain the status quo and others challenging their authority, vying to constitute their own authority, or to simply improve their position within structural limits they dare not challenge?

Discursive legitimation provides insight into this power interplay precisely because it serves as a means by which actors legitimate their own positions and decisions (Haarstad et al. 2018). In an ideal world, it enables deliberation along democratic lines to institute accountability in the manner in which energy transitions are discussed and implemented (Späth and Rohracher 2010). Deliberative democracy remains hard to obtain in most political contexts, and a technical sector like energy hardly lends itself easily to informed public debate and engagement. Given its bureaucratic, often top-down history, a transition in this sector faces a real challenge to engender energy democracy, with the norm having long been to leave decision-making in the hands of narrow groups of experts (Sareen 2018). Examining discursive legitimation, then, is a sound approach to also identify specific opportunities to build public accountability into energy transitions.

\subsection{Bureaucratic Legitimation}

Bureaucratic legitimation pertains to practices, often codified and sequential, that validate some actions and actors and limit the range of possibilities for other actors. Readers will be familiar with bureaucracy as a particular method of ensuring conformity with existing laws and regulations (Ferguson and Gupta 2002). For instance, actors might have to furnish proof of a certain competence or qualification in order to secure approval necessary to take on a formal role, operate a private enterprise or maintain access to public services. Bureaucracy is ubiquitous; it is part of the paraphernalia of daily life whereby we conduct our everyday affairs. It also 
serves essential functions within society and is inevitable. But the flip side is that it accretes redundant requirements, conditions that are an artefact of old ways but remain embedded in current protocols due to inadequate adaptiveness by an organisation during sectoral change. Actors who have to meet such bureaucratic residue might protest and push for a change in formal requirements, an update, or they might find themselves in a position where they are unable to appeal due to limited time, financial wherewithal or a legal framework that, in turn, poses its own bureaucratic challenges. Authorities imposing bureaucratic requirements are often painfully well aware of the privilege their position accords them; depending on internal mechanisms to ensure checks and balances, particular individuals might even seek to abuse this privilege for personal gain, which is usually referred to as petty corruption.

There are several other aspects to bureaucratic legitimation (cf. Suchman 1995), such as a likely bias in favour of incumbent actors, and against emergent actors, on whom falls the onus to validate themselves and fulfil numerous existing requirements - to learn the rules of the game (Geels and Schot 2007). This is a potentially desirable trait in a wellfunctioning system to ensure system reliability and security, but poses challenges when change is imperative as in the case of energy transitions to address the urgent climate challenge. Several other relational tendencies also surface: there are likely to be information flow asymmetries, as practices in most sectors and contexts tend to feature a partially informal component. There is a risk that bureaucratic processes will extend processing time for critical decisions (Crawford 2015), lowering policy visibility during sectoral change and disadvantaging actors who are worst affected by ensuing uncertainty. And there is a further question concerning time and positionality: those who are well placed to devise bureaucratic requirements have often been closely acquainted with a sector for a long period, and hence, their embodied memory is of a certain mode of conducting affairs that is liable to often resemble business as usual (Sareen 2018; Szeman 2013). The bureaucratic mechanisms they proffer might thus favour the status quo and incumbent actors, allowing tacit bias to creep in. This risk is exacerbated by the fact that entrenched actors often occupy key positions from which to lobby and influence decision-makers in their sector; they can challenge and effectively quash protests from emergent actors by pointing to their superior experience and historically stellar credentials. When changes do come about, such actors can again leverage their positions to modulate what new bureaucratic frameworks are put in play 
(Grandin and Sareen in review). This not only equips them with a potential information advantage, it also suggests that key actors can orchestrate sectoral change to unfold in a manner that works to their advantage over others without being held to account for their self-serving exercise of undue influence.

For instance, during energy sector transitions, solar developers might find themselves faced with the need to secure a number of different licences: to lease land for up to three decades, to conduct basic environmental impact assessments, to access grid infrastructure, to import solar modules and to gain the right to provide a certain quantum of stable supply to the electric grid over a stated period or to enter into bilateral contracts with users, to mention a few examples. These constitute practices of bureaucratic legitimation, and actors who are unable to navigate such demands might find themselves shut out from being able to participate as solar developers. An appropriate amount of bureaucratic process is important to secure requisite oversight over a number of interlocked functions in a technical sector like energy (Sareen and Kale 2018); a well-conceived bureaucratic system can feature in-built corrective measures that function as accountability mechanisms, internalised checks and balances. But what complicates matters is when bureaucratic requirements display overly zealous reach or are simply biased towards or against a particular technology or set of actors-especially emerging ones who tend to have less social capital-to an extent that interferes with the efficient functioning of the sector.

Sometimes such bureaucratic interference is expressly permitted and justified on normative grounds - renewable energy may be permitted to go ahead up to a certain component of the total energy supply, so as to meet clean energy targets as a percentage of the grid mix, consequently loosening up bureaucratic requirements for renewable producers up to this target. Yet, normative commitments are not always clearly articulated-fossil fuels are accorded numerous subsidies, both historically in terms of existing energy infrastructure and directly at present, to an extent that other sources would find it impossible to secure through any number of bureaucratic processes (Asmelash 2015). Bureaucratic preferences are not always easy to discern. Wholesale energy trading markets, for instance, follow bureaucratic sets of rules that have evolved historically in energy sectors with relatively small components of renewable energy, and as this proportion changes, the rules do not necessarily change in ways that are optimal for the grid or fair in terms of their effects on various actors, not 
least on the citizens and users whom the energy sector should serve in a manner responsive to their evolving needs. As part of energy transitions, these could include regulatory frameworks for individuals and communities to prosume and receive appropriate compensation for power sold to the grid from rooftop solar panels.

Studying such practices of bureaucratic legitimation can be challenging, but is an essential component of identifying whether and how energy transitions can proceed with public accountability (Kalkuhl et al. 2013; Saltzstein 1979). Such examination must often be undertaken in several locations across multiple scales (Krause and Meier 2005)—down the corridors of power where bureaucracy is executed; in policy documents, where its formal contours are delineated; by listening to the accounts of actors who claim they are marginalised; through attention to emergent material changes that open new possibilities and how these possibilities are bureaucratised; and by triangulating between the various concurrent changes in bureaucratic requirements during sectoral evolution (Sareen and Kale 2018). Where such examination uncovers bureaucratic mediation that forecloses opportunities for energy transition to aid decarbonisation and social equity, these practices can be specifically challenged to build accountability gains within specific contexts of energy transition.

\subsection{Technocratic Legitimation}

Technocratic legitimation refers to a set of practices that perform systematic checks and approval of actions that entail technical expertise. This is distinct from bureaucratic legitimation in that it extends beyond filling forms or ticking boxes to secure validation from a designated authority, to a practice that is itself substantive along the same register as the action that it evaluates for approval. This requires some clarification: practices of technocratic legitimation devise a method to assess whether specific actions by specific actors should be permitted or not, and this method itself exhibits a certain element of sophistication in order to lend credibility to the approval as something that takes place after due consideration of the technicalities involved.

Energy transitions raise many highly technical questions that require expert knowledge and do not always have existing scientific consensus around one answer. There may be several possibilities and a basis is needed to determine which ones to permit and prioritise, and which actors should be in charge of executing them and on what basis (Chilvers and Longhurst 
2016). An important but relatively easy to resolve example is that of the debate between 80 and 100 per cent renewable energy-based systems. While there is still some disagreement on the possibility of complete decarbonisation despite highly detailed analyses of an impressive number of actual contexts in which this should work, it does not complicate too many current decisions, as most energy systems are well short of even 80 per cent renewable energy sources; hence, decisions can be made to decarbonise rapidly, and the question of the final 20 per cent can be resolved later in the energy transition (Jacobson and Delucchi 2009). A more complicated question and one that does require technocratic legitimation is whether a given quantum of new renewable energy capacity can be installed in a decentralised manner and added to an existing electric grid infrastructure. It is important not to overload transmission capacity beyond what the grid can withstand to ensure reliable energy supply and to consider the basis for 'curtailment', which refers to letting surplus power generation simply go unused, or to shutting it down when it runs into grid capacity constraints. Before giving the go-ahead to a number of solar projects, an energy regulator or national ministry would be keen to ensure that the terms on which this new capacity is installed are clear to everyone concerned, marking a clear instance of a case for technocratic legitimation. This is crucial not only to enable energy transitions, but to safeguard citizens against unreliable energy services and debt burdens in case support schemes are not designed to have equitable effects, as well as to prevent losses to the public exchequer, utilities and developers due to inadequate attention to aspects like grid stability and coordination.

This presents an interesting challenge for accountability in energy transitions. When matters are technical, they can hardly be left up to some sort of popular vote, as the public is rarely sufficiently knowledgeable to weigh in usefully on matters of such sophistication. But simply entrusting them to experts risks eventual public backlash, especially in contemporary contexts of rising distrust against authority and the rule of experts; history also bears evidence to the risk of elite capture and large-scale corruption under such conditions (cf. Lennon 2017). Practices of technocratic legitimation present a reasonable compromise-devising a relatively sophisticated system to secure technically appropriate decisions, but with an element of checks and balances and the participation of multiple types of actors who can hold each other accountable. Examples include standing committees, special taskforces and other such ad hoc measures; also more institutionalised mechanisms such as stringent public procurement rules, 
well-defined guidelines for public tenders to ensure competitive bidding on various contracts, and algorithms that automate the allocation of particular opportunities to actors who best fulfil pre-specified and publicised criteria to secure optimal performance.

Yet, both ad hoc and more embedded mechanisms, when situated within a temporal perspective, can be appreciated as facing risks of cooptation and being reduced to an empty shell without securing the very accountable outcomes that their technocratic components are ostensibly put in place to ensure (Hendriks 2009). Actors often move between key organisations in the same sector over time, and collegial and personal networks overlap in complex ways that render secrecy almost impossible, so upcoming changes in assessment or selection routines often set off preemptive adjustments within organisations that are in the loop, even before they are formally announced (Hargreaves et al. 2013). Moreover, sectoral contexts often feature limited expertise within a region or country; hence, expertise is subcontracted in to furnish inputs for terms of reference. This again courts the risk that some well-networked actors may be tipped off in advance of any technocratic legitimation procedures and maximise their chances over competitors.

Probing these relational practices of technocratic legitimation in concrete instances can generate and advance a technically robust and politically informed understanding of energy transitions. Technocratic legitimation is perhaps most visible at times when a sector undergoes rapid change, as effort-intensive mechanisms are put in place to enable change while simultaneously maintaining stability (Pellizzoni 2011). Over time, these practices tend to be absorbed into reconfigured systemic practices and become part of bureaucratic legitimation, which is more routinised and embedded within existing organisational functions. In this sense, practices of technocratic legitimation offer a raw, direct opportunity to shape energy futures towards decarbonisation and enhancement of social equity - by examining, critiquing and adjusting specific practices, it is possible to impact how the energy sector reorientates itself in relation to current changes. This translation function, between experts who are entrusted with framing and conducting technocratic legitimation and the public whose interests they should in principle safeguard, is one that researchers and analysts are well equipped to weigh in on (Fischer 1993). Those who inform themselves of the empirics of technocratic legitimation in a sectoral context can credibly provide policymakers with inputs on specific measures 
they should establish in order to move energy transitions towards sustainability, with a clear basis in evidence.

\subsection{Financial Legitimation}

Financial legitimation pertains to practices, often spatially remote and materially elusive, that enable actors to either block out scope for action, or to fulfil financial requirements and proceed with material actions in order to retain relevance within a sectoral context. They are perhaps the most crucial and telltale signifier of the characteristics of an energy transition-which actors are able to secure financial legitimation, through which practices, for what activities? By structuring the fields of action, capital and access to credit quite directly shape energy transitions (Hess 2014); thus, the practices that make up financial legitimation indirectly capture the core of any sectoral change. One of the refrains iterated by international agencies trying to steer towards rapid global decarbonisation and equitable access to energy has been the need to make much more capital available for universal access to clean energy (also see Polzin et al. 2017); the global divestment movement is trying to push money out of fossil fuel energy to secure contractions of carbon-intensive sources and accelerate investment in renewable energy (Healy and Barry 2017).

Practices of financial legitimation thus render explicit the relevance of spatial and scalar connections. But what practices are observable and how can their study contribute towards more accountable energy transitions? At the household or individual scale, germane issues include determining the appropriate levels of compensation for flexibility added to the grid based on distributed storage, as batteries become affordable and electric vehicles proliferate, as well as disincentives to prevent users from loading the grid during peak demand periods (Sareen and Rommetveit 2019). Several aspects of financial legitimation can in fact be studied in great empirical detail: what are the challenges actors have to face in securing financial backing to install and operate different energy sources; how do these requirements vary across sources; how are these financial parameters set and by which authority? For instance, renewable energy projects face a rather different challenge than fossil fuel projects. Most of their lifetime project costs are concentrated up front: procurement of licences, land and infrastructure. Once equipment is set up and grid connected, operating costs are negligible compared to coal or gas thermal plants which consume a great deal of fuel throughout their lifespan, fuel that additionally often 
has to be brought in from afar. Yet renewable energy projects are often characterised as variable sources and have up to recently faced considerable scepticism from financial institutions regarding their future revenue flows, making it relatively expensive to secure investment capital (Kim and Park 2016).

With the rapid decrease in costs of both wind and, especially, solar energy technologies, these dynamics have begun to shift, and even large fossil fuel majors are beginning to leverage their portfolios with some investments in clean energy. But the challenges are significantly different for relatively small entrants to the energy sector who do not have as much financial weight. By contrast, shell companies have also begun to emerge rapidly as vehicles for speculative financial investments in renewable energy projects. How to maintain an energy sector that remains open to smaller actors while also safeguarding against potentially risky short-term players is a challenge that can only be resolved through a keen appreciation of various practices of financial legitimation (Mazzucato and Semieniuk 2018).

Even tracking these observable practices, however, uncovers only the tip of the proverbial iceberg. When it comes to energy finance, there is little transparency, with large sums and many international organisations involved, leveraging their presence across several different legal regimes including global tax havens. There are thus intrinsic problems to contend with to usher accountability into financial legitimation, and part of the task is to better visualise these global metabolisms at lower scales like the urban and national (Goodman and Marshall 2018). Many cities, regions and countries have begun to track their territorial emissions and set targets at lower scales, including sector specific ones. It is possible that such attempts will be accompanied by fees on high carbon emitters and mass mobilisation of greater investment in renewable energy. Many such initiatives have already been promoted in recent years, but these attempts at alternative financial legitimation have faced stiff resistance in most parts of the world, most notably from the powerful and well-funded fossil fuel lobby that such practices, if successful, directly threaten.

Financial legitimation extends beyond project finance. These practices are also embedded within other processes intrinsic to the everyday operation of the energy sector, such as wholesale and retail market trade. On the wholesale market, fossil fuels such as gas secure high returns due to their flexibility, being available 'on demand', whereas market designs do not always favour renewable energy sources as their percentage of the total supply mix increases rapidly (Ueckerdt et al. 2015). This again is a question 
of what characteristics are seen as worth rewarding financially, and whether the decision is made by default or based on exhaustive public discussion. Likewise on the retail market, rules vary vastly across countries in terms of how much actors such as households and communities can benefit from installing small-scale solar capacity. Another practice of financial legitimation embedded both deeply and historically in the energy sector pertains to investments in energy infrastructure, often made from the public purse, with major consequences for which actors and what energy sources gain support (Jerneck 2017). This support includes both being able to sell electricity to the grid and lowering costs for the energy producer, for instance by co-financing thermal power plant infrastructure by the sea to enable easy access to international coal shipments, a common practice that supports one of the highest carbon emitting sources. Studying the manner in which these issues of financial legitimation are discussed and settled, as well as whom they favour and penalise, can generate key insights into the nature of energy transitions.

Overall, then, practices of financial legitimation are possibly the trickiest to interrogate empirically; doing so is, nonetheless, vital in order to identify the points that warrant the most critical attention for moving towards accountable energy transitions. These practices take place across the spatial scale, but their effects are materialised in the sector, and various reporting mechanisms and mandates as well as investigations by civil society watchdogs render overall trends visible. When it comes to specific actors in a given context, the contrasting demands that financial legitimation places on them can often be clearly explicated, and serve as a basis to challenge and contest practices that maintain power differentials in favour of business as usual. Unpacking this can ease the way for financially competitive renewable energy sources to expand rapidly in a market made more even by bringing accountability into energy sector transitions.

\subsection{Linking Hollow and Substantive Accountability with Sustainability Outcomes}

The articulation of the four types of practices of legitimation that relationally constitute accountability, or the lack of it, in energy sector transitions, paves the way for the final step of the argument in Part I. Overall, any given transition comprises these practices, which can be disaggregated into performances of substantive or hollow accountability. At a 
disaggregated level, most acts can be empirically and relationally categorised as aiding or opposing interlinked shifts towards decarbonisation and social equity under energy transition.

Acts that aid such shifts, and are held to account by practices of legitimation in order to secure a durable outcome of this nature, can be characterised as contributing to a sustainable energy transition. This is a case where practices of legitimation constitute substantive accountability relations. Conversely, acts that oppose such shifts are not substantively held to account by practices of legitimation in the service of sustainable outcomes (Blühdorn 2013). Rather, they are supported by practices of legitimation that constitute a performance of hollow accountability; they support the persistence or even expansion of unsustainable outcomes in the energy sector.

It follows that practices of legitimation provide the basis for a relational toolkit to identify substantive and hollow accountability through empirical study of energy sector transitions. This fine-grained evidencing and analysis of the practices that constitute energy transitions can inform academics, and in turn policymakers, practitioners and the public, about acts that support sustainability and those that hold us back from it. Wielded well, this pickaxe can equip citizens with evidence for their own urgent axes to grind and create a strong push for public accountability to be instituted into energy transitions towards sustainability.

This intent- to contribute to rapid decarbonisation of our energy systems and deeply change whom they benefit, thus addressing climate change drivers and safeguarding public interest-is a guiding beacon. The logical next step after propounding a typology of practices of legitimation is to understand how to situate such an approach within scholarship on energy transitions, so that it can render accountability crises visible in contextualised ways that inform and enable action. To open up space for sustainable outcomes through more accountable governance of energy transitions, it is relevant to take point of departure in the variety of ways in which scholarship on environmental governance approaches accountability in energy transitions. The five case chapters in Part II capture a wide range of cases and different disciplinary perspectives. 


\section{REFERENCES}

Asmelash, H. B. (2015). Energy subsidies and WTO dispute settlement: Why only renewable energy subsidies are challenged. Journal of International Economic Law, 18(2), 261-285.

Blühdorn, I. (2013). The governance of unsustainability: Ecology and democracy after the post-democratic turn. Environmental Politics, 22(1), 16-36.

Boltanski, L., \& Thévenot, L. (2006). On justification: Economies of worth. Princeton, NJ: Princeton University Press.

Chilvers, J., \& Longhurst, N. (2016). Participation in transition(s): Reconceiving public engagements in energy transitions as co-produced, emergent and diverse. Journal of Environmental Policy \& Planning, 18(5), 585-607.

Crawford, A. (2015). Temporality in restorative justice: On time, timing and timeconsciousness. Theoretical Criminology, 19(4), 470-490.

Falkner, R. (2014). Global environmental politics and energy: Mapping the research agenda. Energy Research \& Social Science, 1, 188-197.

Ferguson, J., \& Gupta, A. (2002). Spatializing states: Toward an ethnography of neoliberal governmentality. American Ethnologist, 29(4), 981-1002.

Fischer, F. (1993). Citizen participation and the democratization of policy expertise: From theoretical inquiry to practical cases. Policy Sciences, 26(3), 165-187.

Geels, F. W., \& Schot, J. (2007). Typology of sociotechnical transition pathways. Research Policy, 36(3), 399-417.

Goodman, J., \& Marshall, J. P. (2018). Problems of methodology and method in climate and energy research: Socialising climate change? Energy Research o Social Science, 45, 1-11.

Grandin, J., \& Sareen, S. (in review). What sticks? Ephemerality, permanence and urban transformation pathways. Revised and resubmitted manuscript.

Haarstad, H., Sareen, S., Wanvik, T. I., Grandin, J., Kjærås, K., Oseland, S. E., ... Wathne, M. (2018). Transformative social science? Modes of engagement in climate and energy solutions. Energy Research \& Social Science, 42, 193-197.

Hargreaves, T., Hielscher, S., Seyfang, G., \& Smith, A. (2013). Grassroots innovations in community energy: The role of intermediaries in niche development. Global Environmental Change, 23(5), 868-880.

Healy, N., \& Barry, J. (2017). Politicizing energy justice and energy system transitions: Fossil fuel divestment and a "just transition". Energy Policy, 108, 451-459.

Hendriks, C. M. (2009). Policy design without democracy? Making democratic sense of transition management. Policy Sciences, 42(4), 341.

Hess, D. J. (2014). Sustainability transitions: A political coalition perspective. Research Policy, 43(2), 278-283.

Jacobson, M. Z., \& Delucchi, M. A. (2009). A path to sustainable energy by 2030. Scientific American, 301(5), 58-65. 
Jerneck, M. (2017). Financialization impedes climate change mitigation: Evidence from the early American solar industry. Science Advances, 3(3), el601861.

Kalkuhl, M., Edenhofer, O., \& Lessmann, K. (2013). Renewable energy subsidies: Second-best policy or fatal aberration for mitigation? Resource and Energy Economics, 35(3), 217-234.

Kim, J., \& Park, K. (2016). Financial development and deployment of renewable energy technologies. Energy Economics, 59, 238-250.

Krause, G. A., \& Meier, K. J. (Eds.). (2005). Politics, policy, and organizations: Frontiers in the scientific study of bureaucracy. University of Michigan Press.

Lennon, M. (2017). Decolonizing energy: Black Lives Matter and technoscientific expertise amid solar transitions. Energy Research \& Social Science, 30, 18-27.

Mazzucato, M., \& Semieniuk, G. (2018). Financing renewable energy: Who is financing what and why it matters. Technological Forecasting and Social Change, $127,8-22$.

Moezzi, M., Janda, K. B., \& Rotmann, S. (2017). Using stories, narratives, and storytelling in energy and climate change research. Energy Research \& Social Science, 31, 1-10.

Morgan, K., Cheong, M., \& Bedingfield, S. (2018). "Power to the people!": Social media discourse on regional energy issues in Australia. Australasian Journal of Information Systems, 22. In press, https://doi.org/10.3127/ajis. v22i0.1678

Patriotta, G., Gond, J. P., \& Schultz, F. (2011). Maintaining legitimacy: Controversies, orders of worth, and public justifications. Journal of Management Studies, 48(8), 1804-1836.

Pellizzoni, L. (2011). The politics of facts: Local environmental conflicts and expertise. Environmental Politics, 20(6), 765-785.

Polzin, F., Sanders, M., \& Täube, F. (2017). A diverse and resilient financial system for investments in the energy transition. Current Opinion in Environmental Sustainability, 28, 24-32.

Rose, N. (1999). Powers of freedom: Reframing political thought. Cambridge: Cambridge University Press.

Saltzstein, G. (1979). Representative bureaucracy and bureaucratic responsibility: Problems and prospects. Administration \& Society, 10(4), 465-475.

Sareen, S. (2018). Energy distribution trajectories in two Western Indian states: Comparative politics and sectoral dynamics. Energy Research \& Social Science, $35,17-27$.

Sareen, S. (in review). Metrics for an accountable energy transition? Legitimating the governance of solar uptake. Manuscript under review.

Sareen, S., \& Kale, S. S. (2018). Solar 'power': Socio-political dynamics of infrastructural development in two Western Indian states. Energy Research o Social Science, 41, 270-278. 
Sareen, S., \& Rommetveit, K. (2019). Smart gridlock? Challenging hegemonic framings of mitigation solutions and scalability. Environmental Research Letters. In press, https://doi.org/10.1088/1748-9326/ab21e6

Smith, A., \& Stirling, A. (2010). The politics of social-ecological resilience and sustainable socio-technical transitions. Ecology and Society, 15(1). Retrieved from http://www.ecologyandsociety.org/voll5/issl/artl1/

Späth, P., \& Rohracher, H. (2010). 'Energy regions': The transformative power of regional discourses on socio-technical futures. Research Policy, 39(4), 449-458.

Suchman, M. C. (1995). Managing legitimacy: Strategic and institutional approaches. Academy of Management Review, 20(3), 571-610.

Szeman, I. (2013). How to know about oil: Energy epistemologies and political futures. Journal of Canadian Studies/Revue d'études canadiennes, $47(3), 145-168$.

Szulecki, K. (2018). Conceptualizing energy democracy. Environmental Politics, $27(1), 21-41$.

Ueckerdt, F., Brecha, R., \& Luderer, G. (2015). Analyzing major challenges of wind and solar variability in power systems. Renewable Energy, 81, 1-10.

von Benda-Beckmann, K. (1981). Forum shopping and shopping forums: Dispute processing in a Minangkabau village in West Sumatra. The Journal of Legal Pluralism and Unofficial Law, 13(19), 117-159.

Open Access This chapter is licensed under the terms of the Creative Commons Attribution 4.0 International License (http://creativecommons.org/licenses/ by $/ 4.0 /$ ), which permits use, sharing, adaptation, distribution and reproduction in any medium or format, as long as you give appropriate credit to the original author(s) and the source, provide a link to the Creative Commons licence and indicate if changes were made.

The images or other third party material in this chapter are included in the chapter's Creative Commons licence, unless indicated otherwise in a credit line to the material. If material is not included in the chapter's Creative Commons licence and your intended use is not permitted by statutory regulation or exceeds the permitted use, you will need to obtain permission directly from the copyright holder.

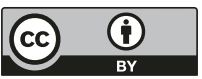

